This text presents and argues the concept of territory and displacement in the contemporarary. It brings some references of the field of the Culture as Bhabha (2005) and Saints $(2004,2006)$ to help to think the art contemporary through the thought of Cauquelin $(2005,2005 a)$ and in this context analyzes the artistic production of Guillermo Go'mez-Peña, Mexican, performance artist, and also a theoretician of the field of the culture.

Keywords: territory, displacement, work of art 


\title{
Território e deslocamento na obra de Guillermo Gómez-Peña
}

\author{
Marilda Oliveira de \\ OLIVEIRA
}

Este texto apresenta e discute o conceito de território e deslocamento na contemporaneidade. Traz alguns referenciais do campo da Cultura como Bhabha (2005) e Santos $(2004,2006)$ para ajudar a pensar a arte contemporânea através do pensamento de Cauquelin $(2005,2005 a)$ e nesse contexto analisa a produção artística de Guillermo Gómez-Peña, artista mexicano, performático, e também um teórico do campo da cultura. Palavras-chave: território, deslocamento, obra de arte 
A proposta deste texto é, inicialmente, tratar da questão conceitual das terminologias - Território e Deslocamento, posteriormente abordar a relação deste campo com a Arte Contemporânea e finalmente apresentar uma produção artística contemporânea que trabalha com estes referenciais do campo da Cultura.

Para esta discussão aporto como principais referenciais: Homi Bhabha - O local da Cultura (2005), Bhabha é crítico indo-britânico e professor de Teoria Cultural da Universidade de Chicago; as contribuições de Milton Santos - Território e Sociedade (2004) e Por uma outra globalização (2006), Milton foi um geógrafo bahiano, professor da USP, falecido em 2001. Anne Cauquelin - Arte Contemporânea: uma introdução (2005) e Teorias da Arte (2005a), professora e crítica de Arte francesa, residente em Paris; Catherine Millet - A Arte Contemporânea (1997), Millet é crítica de Arte e diretora da revista francesa Art Press e Martin Heidegger - Ser e Tempo (2005), Heidegger é um dos filósofos alemão mais importante e influente deste século, falecido em 1976. Outros autores também corroboram com a discussão.

A primeira vez que se publicou algo sobre Território e Deslocamento no campo da Arte foi em 1961. Refiro-me ao crítico americano Clement Greenberg e a seu livro Art and Culture, publicado em Boston. Este livro foi traduzido ao francês em 1988 - Art et Culture: Essais critiques, e ao português em 2001 Arte e Cultura - São Paulo (Ed. Ática).

Para Greenberg (2001) Territorialidade é um espaço de práticas culturais, nas quais se criam mecanismos identitários de representação a partir da memória coletiva, das singularidades culturais e das paisagens; demarcação dos contornos ou fronteiras do território.

A Territorialidade seria então resultante da unidade fictícia, em detrimento das diferenças internas, porém evocando sempre a distinção em relação às outras territorialidades. Território como lugar de produção e reprodução de memórias, de imaginários e sociabilidades; suporte físico de toda a vivência social; área geográfica em que um indivíduo ou grupo desenvolve sua existência. 
Nesse caso a fronteira é algo delimitado, demarcado com contornos bem definidos. Idéia contrária ao pensamento de Heidegger (2005) que sustenta que a fronteira não pode ser vista como um ponto onde algo termina, mas, como os gregos já reconheciam, a fronteira deve ser percebida como o ponto a partir do qual algo começa a se fazer presente (HEIDEGGER, 2005)

Por Deslocamento ou Desterritorialização na contemporaneidade Bhabha (2005) define, como a marca de um cotidiano internalizado por meio de comunicações ágeis e por dinâmicas econômicas globalizantes, onde todos os signos se misturam a acabam por parecer um único e no qual torna-se difícil reconhecer as diferenças; fim das distâncias geográficas e culturais.

Já Haesbaert (2002), vê a Territorialidade como processos múltiplos, diferenciados, complexos da identificação social. Território como simples base material, concreta, de reprodução da sociedade; politicamente uma forma de controle dos indivíduos e/ou dos processos sociais a partir do controle do seu espaço material de existência; culturalmente como espaço dotado de identidade (étnica, nacional, religiosa...) ou seja, de grupos sociais.

Então, Deslocamento ou Desterritorialização podem ser conceituados como a fragilização da vida cotidiana, individualismo e massificação; hibridismo de valores identitários e culturais; uma multiterritorialidade configurada por dois fatores: situar-se num único local físico e deslocar-se por todos os lugares via rede Internet; e, múltiplos territórios/territorialidades acessados pelos deslocamentos físico-geográficos por meio de transportes rápidos que incrementam o multiculturalismo das grandes metrópoles.

Território e Deslocamento se fundem num domínio simbólico que não se limita ao tempo histórico e ao espaço geográfico mas que, dialeticamente, caracteriza o 'ser no mundo' de cada um.

O geógrafo Milton Santos (2004), pondera que o "território em que vivemos é mais que um simples conjunto de objetos, mediante os quais trabalhamos, circulamos, moramos, mas também um dado simbólico" (p. 61). Assim, completa ele, a 
"territorialidade" não provém do simples fato de viver num lugar, mas da comunhão que com ele mantemos" (Ibidem, p.62). Milton Santos defende que Território em si não é um conceito. Território só se torna um conceito utilizável para a análise social quando há deslocamento, quando é móvel. Para este autor "o importante é saber que a sociedade exerce permanentemente um diálogo com o território usado, e que esse diálogo inclui as coisas naturais e artificiais, a herança social e a sociedade em seu movimento atual" (SANTOS, 2004, p. 26)

A partir dessas premissas, qual seria então a relação desse referencial com a Arte Contemporânea?

A obra contemporânea trama em uma só rede (CAUQUELIN, 2005) descentrada, usando a idéia do rizoma como configuração sistêmica proposta por Deleuze \& Guattari na obra Mil Platôs (2006). Um rizoma não começa nem conclui, ele se encontra sempre no meio, entre. A rede: artistas, críticos e público se encontram em um deslocamento contínuo de funções e posições que tornam híbrida a atual produção de arte. Arte contemporânea é rede. Tanto no Brasil quanto fora dele. Essa lógica altera a arte que conhecemos; ela nos distancia dessa arte conhecida não pela simples oposição ou contestação de princípios, e sim pela profunda imersão em um mundo que insiste em se presentificar. O crítico de hoje é aquele que intervém nesse infinito presente ou presente eterno, tornando-o visível a nossas sensações.

O campo da arte, ao longo dos últimos anos vem alterando sua cartografia e ampliando seu território no que diz respeito à historiografia da arte e todo o seu entorno. Um contexto que redimensionou o pensar e o fazer no universo da arte ao desvelar conceitos filosóficos que, indubitavelmente contribuíram para as novas emergências do presente. Idéias que foram incorporadas por muitos pensadores para enriquecer as discussões em torno da arte e formular novos caminhos para as teorias em vigor.

Assim, para Cauquelin (2005a), as teorias da arte se apresentam como um sistema que permite abrir o campo da arte a discursos de gêneros diferentes, isto é, engloba a fala de críticos e historiadores de arte, de semióticos, de fenomenólo- 
gos, de psicanalistas e dos próprios artistas. Uma atividade que constrói, transforma ou modela os discursos da arte e que nos conduz a analisar tipos de ações, em vez de avaliar o conteúdo conceitual das especulações. A partir desse ponto, a autora determina um lugar para cada teoria, bem como para cada tentativa de teorização denominada por ela de 'tipologias de ações possíveis'.

Lugar este que abrange, desde as 'teorias de fundação' - idéias, tonalidades ou ambiências na qual a arte e seu conceito vão se encontrar envolvidos na tarefa de estabelecer regras, princípios e limites à atividade artística -, até as 'teorias de acompanhamento' - teorias que intervém a posteriori e que surgem para 'acompanhar' a arte em suas manifestações e propor explicações quer seja para o fenômeno artístico em geral, quer seja para esta ou aquela obra ou movimento/tendência em particular.

Para Cauquelin (2005a), as teorias da arte se configuram como um rumor que envolve a prática da arte e que, à primeira vista, o que poderia parecer estar fundamentado em opiniões vagas, em humores e gostos pessoais, é na verdade uma espécie de resumo de teorias mescladas que o hábito tonou naturais, evidentes, ou seja, implícitas. Um ouvir dizer... O que se escutou falar... Um rumor traduzido pela doxa. Um gênero de discurso à margem, não absurdo, mas que atua ao lado e fora da lógica, da erudição, do conhecimento preciso. É esse conhecimento difuso, que não se considera conhecimento e que se traduz em geral por opinião, que transporta as teorias da arte e nossa inabalável crença na arte.

Uma crença que nos leva a questionar o sentido das obras e do trabalho artístico. Sentido entendido como significação da obra que abre um mundo onde a fenomenologia, a hermenêutica, a psicanálise e a história da arte se situam. Um mundo que nos leva a refletir sobre a organização da obra, de como ela se manifesta e se especifica como tal.

"A ruptura está consumada e o passado é, a partir de agora, um espetáculo que se pode observar como qualquer outro, com veneração ou com antipatia" (MILLET, 1997, p. 53) O espaço da arte contemporânea é um espaço elástico, onde o mi- 
crocosmos se torna macrocosmos e inversamente. Passa-se de universos extremamente pessoais, muitas vezes confinados, a conglomerados de todos esses universos, em exposições que cada vez mais juntam artistas que representam todas as civilizações. Nunca o sentimento individual de pertença foi tão abordado na arte de forma tão global, universal, territorial.

A idéia da arte contemporânea como cartografia, enquanto mapa é muito oportuna

O mapa não reproduz um inconsciente fechado sobre ele mesmo, ele o constrói. Ele contribui para a conexão dos campos, para o desbloqueio dos corpos sem órgãos, para sua abertura máxima sobre um plano de consistência. Ele faz parte do rizoma. O mapa é aberto, é conectável em todas as suas dimensões, desmontável, reversível, suscetível de receber modificações constantemente. Ele pode ser rasgado, revertido, adaptar-se a montagens de qualquer natureza, ser preparado por um indivíduo, um grupo, uma formação social. Pode-se desenhá-lo numa parede, concebê-lo como obra de arte, construí-lo como uma ação política ou como uma meditação. Uma das características mais importantes do rizoma talvez seja a de ter sempre múltiplas entradas; a toca, neste sentido, é um rizoma animal, e comporta às vezes uma nítida distinção entre linha de fuga como corredor de deslocamento e os estratos de reserva ou de habitação. Um mapa é uma questão de performance. (DELEUZE \& GUATTARI, 2006, p. 22)

Na contemporaneidade vivemos o momento da dessacralização da obra de arte, mediada por museus e galerias. A ação do artista no espaço público, na rua, nos cafés, assim como outros espaços alternativos aproxima a arte do cotidiano e de seus 'degustadores'.

Gilles Deleuze (2006), Jacques Derrida (2001) e Michel Foucault (2000) são filósofos franceses contemporâneos que podem nos ajudar a pensar quem é este novo sujeito 'degustador' da arte contemporânea, sujeito este com toda sua complexidade histórica e cultural, ou seja:

Um sujeito 'descentrado' e dependente do sistema lingüístico, um sujeito discursivamente constituído e posicionado na intersecção entre as forças libidinais e as práticas socioculturais. Um sujeito apreendido em termos concretos, 'corporificado' e 'generificado'; um ser 'temporal', que chega fisiologicamente falando à vida e 
enfrenta a morte e a extinção como corpo, mas que é infinitamente maleável e flexível, estando submetido às praticas e às estratégias de normalização e individualização que caracterizam as instituições modernas. ${ }^{2}$

O pensamento de Derrida (2001), por exemplo, questiona os pressupostos que governam o pensamento binário e sua hierarquia utilizando-se da 'desconstrução' para denunciar, deslindar e reverter essas hierarquias. Além disso, traz a tona o conceito de diferença, ou diffrance (alteridade) - termo de estrutura dupla que em francês significa tanto 'diferir' quanto 'preterir' - e que na sua obra recebem destaque. De um modo geral, seu pensamento explora a natureza da escrita no sentido mais amplo desta diffrance, em que parte da estratégia é dar visibilidade à impureza da escrita e de qualquer identidade.

Já Deleuze (2006) fixa-se no jogo da 'diferença' e 'repetição', que na contemporaneidade suplantou a representação (o mesmo). Assim, diferença e repetição são, com efeito, índices de um movimento na direção de um pensamento não-representacional e radicalmente horizontal. Pensamento que opera em grande parte de acordo com suas próprias normas e conceitos, isto é, não impõe definições e limites entre identidades, em vez disso, à permeabilidade de todos os limites e barreiras. Portanto, o pensamento horizontal expressa com bastante propriedade os termos 'máquinas do desejo' e 'corpos sem órgãos'. Conceitos que impõe um outro pensar a respeito do desejo e do corpo. Desejo aqui baseado não na perda - que é negativa mas que está sempre em movimento e se reformulando, isto é, em processo afirmativo de fluxos e linhas de fuga. Corpo aqui inorgânico, isto é, um corpo político que está sempre em processo de formação e que se produz por uma síntese conectiva e não por imagens ou projeções, ou seja, um 'corpo sem órgãos' rizomático.

No entanto, Foucault (2000), desenvolveu um novo mapa com sua genealogia que se concentra nos conceitos de 'proveniência' e 'emergência', onde as práticas tornam-se modos de pensamento com lógica, estratégia, evidência e razão. Assim, mais do que estudar movimentos no pensamento à maneira das histórias das idéias, faz uma análise do regime de práticas, isto 
é, se detém na linha entre 'dizer e fazer', 'ver e falar', que são sempre instáveis. Regimes que não podem ser reduzidos a uma forma de história, ou seja, se aventurar a 'projetar sentido na história'. Na verdade, tudo o que temos são efeitos materiais e atos matérias, pois não existe nem um sujeito (ação) e nem uma história (ordem) essencial. A ordem é a própria escritura da história que é sempre elaborada pela perspectiva do presente, uma vez que preenche uma necessidade atual. Aqui a história será entendida como apenas uma orientação para este presente, uma vez que, este presente está sempre em processo de transformação, o que significa que o passado está sempre sendo reavaliado, assumindo assim novos sentidos.

Uma genealogia que está intimamente ligada ao conceito do presente e à sua constante reavaliação do passado. Uma história escrita à luz de preocupações atuais, comprometida com questões do momento presente que intervém no agora; ou seja, uma história efetiva escrita com uma intenção atual, onde o conhecimento é ligado ao poder; poder que não tem qualquer conteúdo substantivo e que passa a ser visto como uma tecnologia. Um poder onde a subjetividade é o resultado de práticas discursivas. Um processo onde a subjetivação, segundo Deleuze (2006, p. 123),

não pode se confundir com o sujeito, a menos que se destitua este de todo a sua interioridade e mesmo de toda identidade. A subjetivação sequer tem a ver com a 'pessoa': é uma individuação particular ou coletiva, que caracteriza um acontecimento (uma hora do dia, um rio, um vento, uma vida...). É um modo intensivo e não um sujeito pessoal. É uma dimensão específica sem a qual não se poderia ultrapassar o saber nem resistir ao poder.

Assim, Foucault (2000) nos apresenta um sujeito que é "se" - a terceira pessoa - é ela que se deve analisar. Fala- 'se', vive'se' e morre- 'se'. O sujeito existe, mas ele é sempre uma derivada; ele nasce e 'se' esvai na espessura do que 'se' diz, do que 'se' vê.

Nesse sentido se desconstrói verdades, se desconstrói a idéia que veicula à verdade e à liberdade. Essa concepção nos ajuda a compreender porque falar, dizer a própria palavra, nem sempre significa autoria da palavra dita. Discursos poderosos 
impregnam as vozes e fazem desaparecer o sujeito singular que fala. Logo, poder falar não significa, necessariamente, conscientização e muito menos autoria. O que poderia fazer a diferença, segundo Foucault (2000), é o questionamento das forças que produzem os discursos.

Todos esses pensadores enfatizam que o significado é uma construção ativa, radicalmente dependente da pragmática do contexto, questionando, portanto, a suposta universalidade das chamadas 'asserções de verdade'. Todos eles questionam o sujeito cartesiano/kantiano/humanista, ou seja, o sujeito autônomo, livre e transparentemente autoconsciente, que é tradicionalmente visto como a fonte de todo o conhecimento e da ação moral e política. Todos propõem o descentramento da questão do sujeito para a da subjetividade que passa a dar ênfase à instância fundadora da intencionalidade. Trata-se, conforme aponta Félix Guattari (2000, p. 35) de "tomar a relação entre sujeito e o objeto pelo meio, e de fazer passar ao primeiro plano a instância do exprimir". Ou, em outras palavras:

cada indivíduo, cada grupo social veicula seu próprio sistema de modelização da subjetividade, quer dizer, uma certa cartografia feita de demarcações cognitivas, mas também míticas, rituais, sintomatológicas, a partir da qual ele se posiciona em relação aos seus afetos, suas angustias e tenta gerir suas inibições e suas pulsões. (GUATTARI, 2000, p. 22)

Passamos então para uma outra questão, onde se recolocará a questão do conteúdo, que participa da subjetividade dando consistência à qualidade ontológica da expressão, e conseqüentemente da função existencial.

É, portanto, nestes conjuntos de condições que se torna possível que instâncias individuais e/ou coletivas estejam em posição de emergir como território existencial auto-referencial em relação a uma alteridade, ela mesma subjetiva, que passaremos a descrever a subjetivação que se opera entre o filósofo/ historiador e a obra de arte. 


\section{Arte e Cultura como demarcadores do espaço}

A performance "Mapa" é uma produção artística contemporânea que trabalha com estes referenciais do campo da Cultura. A obra é do artista performático e escritor, Guillermo Gómez-Peña, mexicano. Guillermo participou da 5a Bienal do Mercosul, Porto Alegre, RS na Usina do Gasômetro. Naquela ocasião apresentou uma "instalação humana", denominada "Mapa", que consistia em uma mulher nua com agulhas sendo distribuídas por todo seu corpo. Cada agulha carregava uma bandeira, dos Estados Unidos, Inglaterra e Israel, em uma manifestação contra a guerra travada pelos Estados Unidos contra o Iraque. Enquanto as bandeiras eram colocadas na mulher, Guillermo leu um texto que envolvia vários idiomas. No fim da performance, o público foi convidado a retirar as bandeiras uma por uma.

Guillermo é um dos mais iconoclastas, perturbadores e excitantes artistas da atualidade nos Estados unidos, mora em São Francisco (EUA) desde os 23 anos, onde é o diretor artístico do Pocha Nostra, um grupo artístico que conta com mais de trinta colaboradores distribuídos em diferentes países: México, EUA, Inglaterra, Espanha e Austrália. Os projetos do Pocha Nostra envolvem desde performances individuais até grandes instalações interativas que incorporam comunidades efêmeras de artistas e intelectuais.

O Pocha Nostra questiona as mitologias do mundo da arte tradicional que apresenta o artista como um boêmio angustiado e gênio mal entendido. Os artistas do Pocha Nostra se concebem a si mesmos como críticos sociais e tradutores interculturais.

Gomez-Peña nasceu em 1955 e cresceu na Cidade do México, foi para os Estados Unidos em 1978. Seu trabalho pioneiro em performance, vídeo, rádio, instalação, poesia, jornalismo e teoria cultural, explora temas sobre cruzamentos culturais, imigração, política da linguagem e arte digital.

E então podemos perguntar-nos: Que pensamento norteia a produção de arte atual? A idéia de "padrões aos pedaços" sugere uma situação paradoxal: ao mesmo tempo em que poderí- 
amos supor que os modelos ou padrões do modernismo foram esgotados, a arte contemporânea navega sobre a profusão de referências da história da arte e, ao mesmo tempo, não há padrões ou modelos novos...Ou há?

A questão que aqui se coloca é - ainda é possível pretender que a arte venha a quebrar paradigmas? É preferível pensar que a arte contemporânea seja prospectiva, propositiva, pois desta forma é possível que surjam novas rupturas, novas resistências, novas interações e assim novas tensões.

O processo histórico contemporâneo tem matizado a necessidade de se colocar pauta a temática da diversidade, da formação/configuração de grupos sociais que são compostos por categorias como gênero, geração, raça/etnia, território e classe.

Nesse sentido, essa sessão tem como objetivo a análise histórica no que se refere às múltiplas expressões acerca da construção/reconstrução de processos identitários e culturais no campo político. Nesse sentido também - Território e Deslocamento apresentam-se na arte contemporânea ainda como temática, não chegam a ser considerados tendência.

Que novas questões estamos desafiados a pensar? O debate contemporâneo tem sinalizado para a necessidade de pensarmos os hibridismos, mestiçagens e mediações culturais que perpassam a relação entre cultura popular e identidade nacional, entre o fazer da cultura e a relação com o saber erudito, principalmente o produzido por folcloristas, etnólogos e antropólogos.

A obra de Guillermo Gomez-Peña que atua sempre em parceria com Roberto Sifuentes ajuda-nos a pensar essas relações que articulam a dificuldade de comunicação trans-cultural, e em especial a relação de conflito entre as culturas norte e sul americanas.

Nas palavras de Guillermo "México é California, Marrocos é Madri, Turquia é Frankfurt, Honduras é Nova Iorque, Argelia é Paris, Nicarágua é Miami, Camboja é São Francisco, Paquistão é Londres, sua casa é minha, sua língua também é minha, seu coração vai ser meu hoje à noite, é a força do Sul, o Norte se evapora, de repente vocês percebem que perderam suas casas, 
suas terras, numa trans-geografia louca... "3

Suas performances e intervenções artísticas - sempre recheadas com 'temperos' e ironias sobre a visão norte americana da cultura latina - incluem o simulacro de uma intervenção-pirata numa estação de TV, transmitida ao vivo para os Estados Unidos por um canal de TV comunitária, o 'Virtual Reality Sombrero' (uma ironia sobre os capacetes de alta tecnologia usados nos experimentos de Realidade Virtual), e o 'Cyber-Bandana' (em que o lenço de cabeça funciona como uma ironia dos aparatos de navegação no ciberespaço).
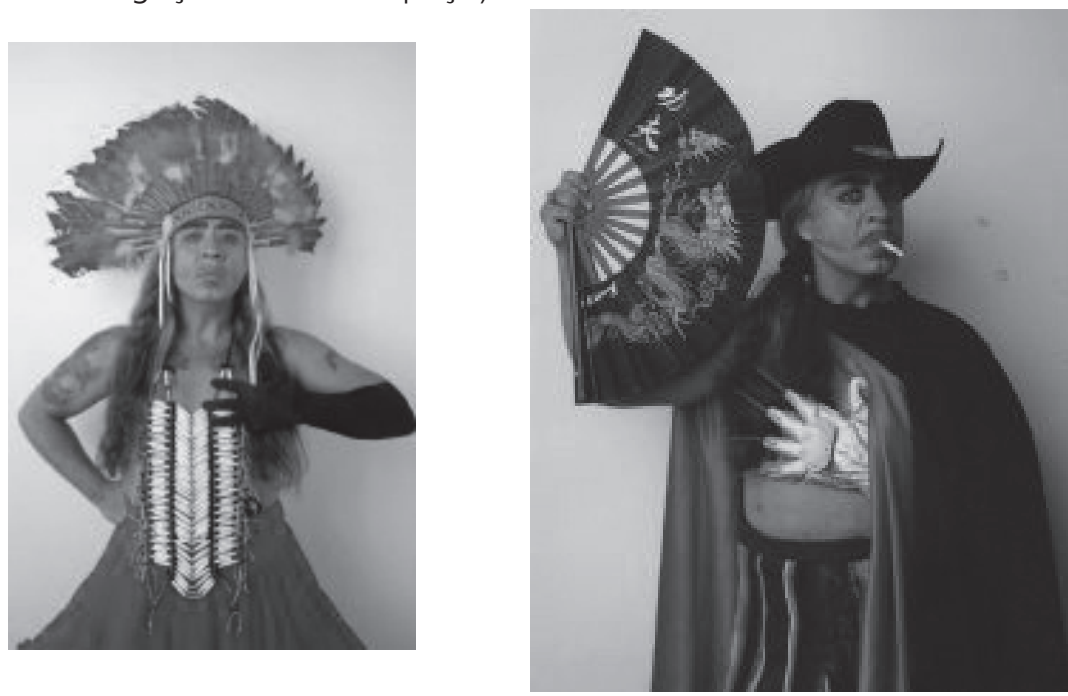

Outra de suas performances são as "confissões": Guillermo e Roberto se caracterizam como 'santos mexicanos' ou como 'marginais latinos' - com todos os adornos e fetiches de cada estereótipo - e ficam 'expostos' durante horas em vitrines de vidro, e o público é convidado a gravar suas confissões sobre sua visão da cultura mexicana, e da influência latina. Eles apresentam, em seus depoimentos, alguns trechos dessas confissões, que incluem fantasias sexuais, interesse e curiosidade, a preconceitos, distorções e agressividade.

Segundo Guillermo, a disparidade do desenvolvimento tecnológico existente entre o Primeiro e o Terceiro Mundo está levando a uma situação de desigualdade social ainda maior: 
"Dada à natureza da cartografia desses novos tempos, aqueles que vivem ao sul da fronteira digital foram forçados a aceitar, novamente, o desagradável, mas necessário, papel da marginalidade... Bandidos da "information superhighway", ciber-imigrantes sem documentos, techno- piratas, coiotes virtuais...". 4

A questão é que nos últimos trinta anos observa-se uma revalorização do corpo na arte. Hoje, o corpo desencadeia um grande número de pesquisas. O corpo passou a ser objeto de reflexão, de estudo, de saber e também de experimento.

O corpo na obra de Guillermo Gómez-Peña é pleno de devir, ávido por transformações. A linguagem da performance na obra de Guillermo Gómez-Peña provoca um questionamento da arte e sua relação com a cultura, com a vida. A performance institui-se como uma forma de arte 'vivencial' onde o artista vivencia a arte como experiência, na qual encontra-se inserido, uma vez que suas atitudes adquirem, nesse espaço/tempo ou território/deslocamento um caráter transformador através da própria experiência.

A linguagem da performance apresenta-se como uma maneira de romper com as categorias do passado e como forma de indicar novas possibilidades uma vez que permite a manipulação da realidade como criação, como invenção de novas realidades, modificação. O discurso artístico não apenas se pronuncia sobre uma realidade mas estabelece diálogo como os acontecimentos do seu tempo.

A performance instaura uma temporalidade não cotidiana, não computável, assim como num ritual, implicando os sujeitos como participantes, interatores e será o público de cada país, estado ou região, de cada 'não-lugar' quem determinará seu tempo. A obra de Guillermo tem uma vertente transitória e fugaz, ligada a pequenas parcelas de tempo, assume significados sobrepostos, realizando a contestação de espaço social e criando espaços diferenciados, alternativos, 'lugares outros', que valem pela experiência que proporcionam.

O que fascina numa performance é a processualidade, a seqüência, os fatores constitutivos, sua relação com o público num determinado espaço/lugar.

O discurso do corpo é, talvez, o mais complexo modo de discur- 
sar, derivante da multiplicidade de sistemas semióticos desenvolvidos pela sociedade. Isso explica as dificuldades em reter sua dinâmica e seu desenvolvimento característicos. Face à linguagem do corpo, evoca-se o problema da legitimidade de uma análise com o objetivo de investigar o tema do corpo na arte. Se, segundo F. Rastier, chamamos comportamento ao conjunto de todos os gestos e atitudes observados ou representados a partir do corpo humano, ambos os aspectos implicam, no terreno da performance, uma metalinguagem que os toma a sua observação e os re-significa, isto é, agrega novos significados a eles. (GLUSBERG, 2003, p. 57)

Além da idéia da cartografia/mapa trabalhada como proposição por Guillermo outra temática muito freqüente em seus trabalhos é a questão da Identidade.

Então, quem é o artista Guillermo Gómez-Peña? É um cruzador de fronteiras de ofício. É alguém que aspira falar do centro, ser um rizoma, um artista que deseja ser ativo no seu fazer cultural. Alguém que quer falar de um lugar que diz respeito não apenas a uma etnia específica, mas a toda uma sociedade.

A identidade não é uma qualidade inerente a uma pessoa, ela nasce da interação com os outros, ou seja, as identidades são construídas no discurso, sendo, portanto fragmentadas, contraditórias e ambíguas. É nesse processo que construímos a história de nossas vidas, nossa história, a história que contamos aos outros como nossa. Os significados que, portanto, construímos sobre o mundo e sobre as pessoas são ideológicos, no sentido que incorporam visões particulares e contribuem para a produção, reprodução e transformação das relações de dominação. (MOITA LOPES, 2002) Sendo assim, concordamos com Foucault (2000, p. 32) quando ele diz que: "A história, genealogicamente falando, não tem por fim reencontrar as raízes de nossa identidade, mas, ao contrário, se obstinar em dissipá-la; ela [a história] não pretende demarcar o território único de onde nós retornaremos; ela pretende fazer aparecer todas as descontinuidades que nos atravessam". Essa é a pretensão deste texto, mostrar as diferentes possibilidades de pensar a arte e a cultura a través de um pensamento contemporâneo, perceber suas descontinuidades num determinado tempo e espaço.

Aprendemos que qualquer estudo sobre identidade deve 
ser localizado num espaço e num tempo concreto (OLIVEIRA, 2004). Tempo só existe porque pode ser materializado em espaço; espaço só existe porque está envolvido na dinâmica do tempo. (HAESBAERT, 2002) Tempo e espaço são referências fundamentais em nossas vidas. Ao tentarmos suprimir um ou outro, podemos estar suprimindo nossa própria identidade. O paradoxo se desfaz quando entendemos que a identidade é um lugar que se assume, uma costura de posição e contexto, e não uma essência ou substância a ser examinada.

"Há entre os membros de uma sociedade, um certo grau de consenso sobre como classificar as coisas a fim de manter alguma ordem social. Esses sistemas partilhados de significação são, na verdade, o que se entende por cultura" Woodward (2000, p.41). O que este conceito sugere é que cultura não é apenas uma viagem de redescoberta, uma viagem de retorno, não é uma arqueologia. A cultura é uma produção. Tem sua matéria-prima, seus recursos, sua história. História esta que está sempre sendo produzida, em processo de formação. Não sendo, portanto, uma questão de ser, mas de tornar-se. O coeficiente de pertença do homem contemporâneo não é absoluto. Vale lembrar aqui Bauman (2000) em "modernidade líquida" quando ele nos projeta num mundo onde tudo é ilusório, onde a angústia, a dor e a insegurança causadas pela vida em sociedade exigem uma análise paciente e contínua da realidade e do modo como os indivíduos são nela inseridos. O pertencimento e a identidade não têm a solidez de uma rocha, não são garantidos para toda a vida, são bastante negociáveis e revogáveis. As decisões que tomamos, as escolhas que fazemos, os caminhos que percorremos, tudo determina quem somos em determinado momento e a qual grupo social pertencemos.

O homem é tido como um ser social que cria a cultura, junto com suas condições, integrado no seu contexto, criando formas de viver, refletindo sobre elas e dando respostas aos desafios que encontra em seu percurso. A cultura, portanto, constitui-se na aquisição metódica da sua experiência humana, criadora e crítica, não apenas aquisição de informações justapostas. Pode-se dizer então, que o homem cria e cultiva a sua cultura, tendo como resultado os desafios propostos pela 
natureza, pelos homens que o rodeiam, ou que o procedem. Nenhuma cultura é jamais unitária em si mesma, nem simplesmente dualista na relação do 'eu' com o 'outro'.

O campo da cultura é complexo e conflituoso, na medida que falamos na edificação de significados, partilhados ou não de aspectos principais da vida individual e social. Podemos dizer também que é escorregadiço e complexo o campo no qual se desenvolvem discussões, propostas e negociações que visam promover o respeito à diferença e a pluralidade cultural.

Finalmente, a arte contemporânea rompeu fronteiras e desloca-se numa imensa cartografia que permite múltiplas leituras, infindáveis relações de infinitos territórios.

\section{Notas}

1. Doutora em História da Arte (1995) e Mestre em Antropologia Social (1990) ambos pela Universidad de Barcelona - Espanha. Professora

2. Michael Peters disponível em <http://www.rubedo.ppsc.br> Acessado em 12/08/2007.

3. Entrevista com o artista, disponível em <http://www.pochanostra.com>

4. Entrevista com o artista, disponível em <http://www.pochanostra.com>

\section{Referências}

BAUMAN, Zygmunt. Identidade: entrevista a Benedetto Vecchio. Tradução de Carlos Albert Medeiros. Rio de Janeiro: Jorge Zahar Ed., 2005.

BHABHA, Homi K. O Local da Cultura. Tradução de Myriam Ávila et al. 3a reimpressão. Belo Horizonte: Ed. UFMG, 2005.

CAUQUELIN, Anne. Arte Contempornea - uma introdução. Tradução de Rejane Janowitzer. São Paulo: Martins Fontes, 2005.

Teorias da Arte. São Paulo: Martins, 2005a.

DELEUZE, Gilles. Conversaes. São Paulo: Editora 34, 2006.

DELEUZE, Gilles; GUATTARI, Félix. Mil Plats. Vol. 1. 4aㅗ reimpressão. Rio de Janeiro: Editora 34, 2006.

DERRIDA, Jacques. Posies. Belo Horizonte: Autêntica, 2001.

FOUCAULT, Michel. As palavras e as coisas: uma arqueologia das ciências humanas. Tradução de Salma T. Muchail. 8 ${ }^{\underline{a}}$ ed. São Paulo: Martins Fontes, 2000.

GUATTARI, Félix. Caosmose: um novo paradigma estético. São Paulo: 
Editora 34, 2000.

GLUSBERG, Jorge. A Arte da Performance. Tradução de Renato Cohen. São Paulo: Perspectiva, 2003.

GREENBERG, C. Arte e Cultura. Tradução de Otacílio Nunes. São Paulo: Ed. Ática, 2001.

HAESBAERT, Rogério. Fim dos territórios ou novas territorialidades? In: MOITA LOPES, Luiz Paulo da; BASTOS, Liliana Cabral (Orgs.) Identidades: recortes multi e interdisciplinares. Campinas, SP: Mercado de Letras, 2002. p. 29-51.

HEIDEGGER, M. Ser e Tempo. 14ª ed. Petrópolis, RJ: Vozes, 2005.

MILLET, Catherine. A Arte Contempornea. Lisboa: Inst.Piaget,1997.

MOITA LOPES, Luiz Paulo da. Identidades Fragmentadas: a construção discursiva de raça, gênero e sexualidade em sala de aula. Campinas, SP: Mercado de Letras, 2002.

OLIVEIRA, Marilda Oliveira de. Identidade e Interculturalidade - História e Arte Guarani. Santa Maria: Editora Ufsm, 2004.

SANTOS, Milton. Território e Sociedade. $2^{\underline{a}}$ reimp. São Paulo: Ed. Fundação Perseu Abramo, 2004.

Por uma outra Globalizao - Do pensamento único à consciência universal. 13aㅡ ed. Rio de Janeiro: Record, 2006.

WOODWARD, Kathryn. Identidade e Diferença: uma introdução teórica e conceitual In: SILVA (Org.) Identidade e Diferena. RJ: Vozes, 2000.

\section{Sites}

<http://www.pochanostra.com> Acessado em 15/08/2006

<http://www.levity.com/corduroy/pena.htm> Acessado em 15/08/2006

<http://www.eldespertador.info/despierta/texdesper/guatinau.htm> Acessado em 20/12/2006

<http://www.rubedo.ppsc.br Acessado em 12/08/2007>

\section{Marilda Oliveira de Oliveira}

Professora Adjunta III do Departamento de Metodologia do Ensino, Centro de Educação, Universidade Federal de Santa Maria (UFSM/RS). Professora do Programa de Pós-Graduação em Educação, PPGE, Centro de Educação, e do Programa de Pós-Graduação em Artes Visuais, PPGART, Centro de Artes, ambos da UFSM/RS. Doutora em História da Arte (1995) e Mestre em Antropologia Social (1990), ambos pela Universidad de Barcelona, Espanha. Bacharel e Licenciada em Artes Visuais pela Universidade Federal de Santa Maria - RS (1987). E-mail: marildaoliveira27@gmail.com 